\title{
The Study of Bedside Handover
}

\author{
Article Review by Toini De Almeida \\ Nursing, Texila American University, Namibia \\ Email:-nelineli95@gmail.com
}

\section{Introduction}

Namibia as a country is not an exception to adverse events due to inadequately managed beside handover. The country has similar contributing factors which may cripple the inefficiency of patient handover, for instance high patient turnover in wards, lack of specific handover guidelines in public hospital settings. Bedside handover are overlooked in its importance as in the case of Namibia where it can be regarded as the possible cause of death (that is still under investigation). From this study support this phenomenon as $60 \%$ of the respondents indicated that they are neutral on such a high-risk matter where they were supposed to be highly alerted. Currently, bedside handover in public hospitals is a day-to-day communication event by the health professionals. However, in Namibia information conveyed is not structured and the patient participation is not stressed. There is a constant outcry of the implications of inadequate bedside handover in the public health facilities. A recent example which ended up in litigation is where a registered nurse was involved with a high risk pregnant woman who was admitted to a public hospital for an elective caesarean section for the following day, but since it was a public holiday (May 1), the operation was not performed. Subsequently the patient died (New Era, 29 April 2014). This case is possibly a result of miscommunication during the handover process and shows a lack of accountability.

Bedside handover has become the most useful way of communication however, it does not happen in vacuum as it is bounded to a legal obligations as stated in American Medical Association (AMA) in its definition that handover is an action of transferring of responsibility and accountability for patient care from one provider or team of providers to another (AMA 2006). Therefore, all nurses are expected to be responsible as individuals, and to use their knowledge and skills to achieve high accountability levels at their health institutions. The goals of the Joint Commission on Accreditation of Healthcare Organizations (JCAHO), requires a standardized approach to handover communication that in-particular allows for the opportunity to ask and answer questions accurate, current information about a patients care, condition, and recent or anticipated changes (2006:37). Effective communication with a patient during total hospital stay is a difficult task due to high patient turnover and time constraints (Catchpole 2007.) Thus, in most cases handover information may be given in a hurried manner, which may compromise the care of patients involved. Nursing staff carries a heavy workload daily as wards are understaffed (Report of Commission of Enquiry into Health Industry 2014). In such situation it is evident to face challenges with various clinical responsibilities within the hospital setting. One of these responsibilities is to communicate effectively and to recognize the risks involved in bedside handover process in order to safeguard and ensure continuity of care. The respondents of this study are not sensitive enough towards bedside handovers and they are lacking knowledge of the significance of basic teamwork skills to allow the team to work in harmony and to coordinate bedside handover meetings successfully. Due to the fact that most respondents are neutral to disagree which is an indication that they are not fully aware that it can result in adverse events such as medical errors; prolonged patient stay in hospital and delay in treatment and care.

Furthermore, it is internationally recognized that, with any patient handover there is a likelihood of risk involved and errors in handover can be fatal to the patient outcome (Manser 2013). Jones stated that cognitive errors occur; nurses' clinical decisions may be inaccurate and associated with inappropriate interventions that can lead to increased and untimely patient 
South American Journal of Nursing

Special Edition 2016

mortality (Jones 2012). Furthermore, Thurgood stated, that patient reporting is a task that repeatedly testing nurse's knowledge, skills and communication (Thurgood 1995).

Given the fact that a constant movement of new nursing graduates entering hospital settings, it is imperative they bear adequate knowledge and skills to organize a seamless, error free bedside handover. Thus, this project focused of the knowledge about bedside handover elements such as preparation, introduction, information exchange, patient involvement and safety scan and some adverse event that may take place during the bedside handover process. Thus, this study aimed at assessing the knowledge regarding the importance of bedside handover procedure; the awareness of implications; and to verify the knowledge of the practical application amongst the final year Bachelor of Nursing Science students at the University of Namibia, Main Campus.

\section{Literature review}

Literature Review for this study is woven around the objectives and it is used as the themes of the study and how it is discussed. The objectives are:

- To determine the if the correct preparation procedures is known

- To identify perils during bedside handovers.

- To verify knowledge of effective practical application of bedside handover.

Patient handover is considered to be a very complex communication situation as stated by Kerr, which occur among a very diverse health team on a daily basis (Kerr 2001). Currently the patient acuity is adding some constrained of efficiency in information sharing. Current studies on bedside handover suggest that healthcare environments experience problems with respect to knowledge sharing during handover (Jacobs and Roodt 2007). However, Sexton stated that bedside hand over was noted as the preferred option of transferring information and is a widely used method within developed protocols (Sexton 2007).

Communication has diverse challenges and according to Wood, we need to understand the complexity of handover better to grasp the challenges. Mbomba stated that it has been discovered that poor communication handovers have resulted in adverse events, such as delays in treatment, error in medication and these may decrease the level patient satisfaction with patient engagement as chance to clarify and cross -check is set (Mbomba 2005).

Therefore, it is imperative for the nurses be certain of bedside usage and its expectation. Mayor alludes that task uncertainty may cause handover duration to be too long, resulting that some patients are given a thorough handover and other are hurried off (Mayor, 2014).

Brixey stated that interruption are frequent events in health care settings as it interrupt the routine nursing activities as well, including bedside handover resulting in decrease efficiency which contributing to medical errors (Brixey 2005). Brixey emphasized to recognize that distraction may lead to wrong site surgery procedure and robust leadership in good prepreparation for bedside handover, prior updating the handover records, informing patient and staff for pending handover might aid to avoidable interruptions and create a opportunity to increase a continues flow of information exchange (JCAHO 2006).

In fact, the main focus in bedside handover is patient safety; Jeffcott (2009) confirms that, report of errors and fatalities in healthcare that may be directly attributed to inefficiencies of the handover process. It has been reported that poor handover is influenced by the lack of structure in how handoffs According to McCann, McHardy et al. $60.9 \%$ of doctors in a New Zealand hospital have experienced clinical problems caused by poor handovers (McCann, McHardy et al. 2007). Furthermore, 31\% of doctors surveyed in the United States have also experienced clinical problems during their shifts that could have been avoided with more efficient handovers (Borowitz 2008). Surprisingly, researchers who studied the styles of handover, McKenna's and Pothier did not propose any specific efficient style (McKenna's 1997) (Pothier 2005). It is important to conclude instead, that no documented technique emphasizing best practice in patient handover.

Parker argues that bedside handover shows to be futile, an Australian study concluded that bedside handover was less efficient as it was often simply a recitation of fact rather than 
interpretation of the patient's condition (Parker 1992).

Sexton (2004) that if information presented, happen to be irrelevant, repetitive, speculatively it is due to lack of guidelines of patient handover whereby the structured information is conveying was not in a systematic way (Nadzam 2009) resulting in poor communication handover, Alvarez \& Coiera stated that it creates some gaps in knowledge regarding patient needs and changing condition, establishing the opportunity to err in clinical decisions with potential to impact patient safety (Alvarez \& Coiera 2006). McMurray conducted a study concluded that bedside handover provides opportunity for patient to be an active participant in process as they can amend the inaccuracies in information being communicated, however, exclusion criteria may rise non participation communication dilemma (McMurray 2011). Critiques of bedside handover states, that patient confidentiality is compromised as other patients can over hear what is being said about a particular patient, however, if professional accountability is adhered to, sensitive information management effectively, for instance avoidance of technical jargon however an informed choice of patient's consent is crucial as it determine the handover style as well (Lu 2013). Chaboyer suggested that to maintain bedside handover confidentiality integrity nurses should lowering their voices in sharing sensitive information and being away from the bedside, use of written information gives a back-up in continuity care (Chaboyer 2008).

However, handovers have been acknowledged as an important part of a nurse's learning experience participants indicated that they received little or no training as part of their formal education on how to conduct handover (Wolf 1989). Furthermore, Lu agreed that attention is needed to ensure that adequate training is provided to nurse in order to minimize medical jargon (Lu 2013). Additionally, Pfaff (2014) identified that new graduate nurses often lack confidence in inter-professional interactions, and this may compromise the delivery of safe and effective healthcare (Pfaff 2014).

\section{Methodology}

The research design was chosen, to determine if nursing students in Namibia know and understand the importance of bedside handovers. It is considered that because the fourth year students are advance students and they should be ready to enter full time employment and render a proper service. There are about eighty final year nursing students and about 42 students took part in this study. The quantitative method is used to emphasize objective measurements statistical, mathematical, or numerical analysis of data collected through questionnaires, that could provide a generalized feeling about the current practice of bedside handovers. Purposeful sampling was used on a tool that was designed to cover all objectives and piloted as well as adjusted before authentic data collection. Purposeful sampling was done with a sample of final year nursing students. They had to respond after they wrote an examination. Firstly they are not skilled in bedside handovers and neither are they knowledgeable. The tool (questionnaire) covered questions under 3 themes such as:

- To determine the if the correct preparation procedures is known

- To identify perils during bedside handovers.

- To verify knowledge of effective practical application of bedside handover.

The objectives are the foundation for two overarching themes and the questions on the questionnaire are interwoven to gather that specific data. Fourth year students who are assumed to be the most advance of the nursing students component are selected as respondents. The total number of respondents is the sample that was selected of 42 students (the sample size was 42 which is $n=42$ ). The data collection method is a questionnaire with closed questions is easy to use and coded and they give the respondents the chance to choose from two or more fixed alternatives. Most closed questions use scaling to ensure uniformity in response and one of the most widely used scales are the Likert scales. The scale allowed for respondents to be asks to respond in one of the following ways: strongly agree, agree, and disagree. The sample selected was done purely on the availability of students. Actually such study should be conducted with full time nursing staff to get a more reliable outcome. The 
South American Journal of Nursing

Special Edition 2016

research instrument is a predesigned questionnaire with close-ended questions that was piloted and amended before the actual data collection started. The procedure of the study was to get permission for the study from the Nursing faculty, from individual respondents and they were all promised confidentiality, as (ethical requirement as per all research studies), when they gave their permission to conduct the study. A specific date was arranged for conducting the questionnaire, up to data collection. The data analysis is orderly arranged data from the questionnaires that are summarized and the similarity, differences and variables be highlighted concerning the bedside hand over into meaningful information.

\section{Analysis}

\subsection{Below are the data in graphs and summary table, analyzed in Excel.}

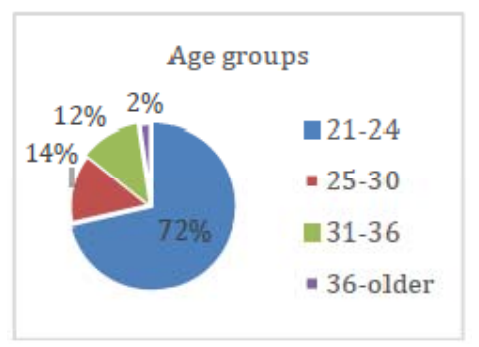

Figure. 1

Table. 1

\begin{tabular}{|l|l|l|l|}
\hline No: & Group & Total number & Percentage \% \\
\hline 1 & $21-24$ & 30 & 72 \\
\hline 2 & $25-30$ & 6 & 14 \\
\hline 3 & $31-36$ & 5 & 12 \\
\hline 4 & 36 and older & 1 & 2 \\
\hline
\end{tabular}

In the Figure 1 and Table 1, above is a condensed version of all the ages of the participants in this study. All the respondents are final year nursing students and most of them are between the ages of $21-24$ years and for this study, it represents $72 \%$ of the total population. Six of the students are older and belongs to the category 25 - 30 and they represent $14 \%$ of the total population. A further group of 5 respondents are a bit older and belongs to the age group category of $31-36$ and they are composition of $12 \%$ of the total pollution of this study. One student who took part in this study are older than 36 . The responses for this study can be regarded as valid as the respondents are mature adults and these mature respondents are a $72 \%$ of the total respondents. This contributes to consider this study as valid and reliable and the outcome and recommendations should be considered accordingly

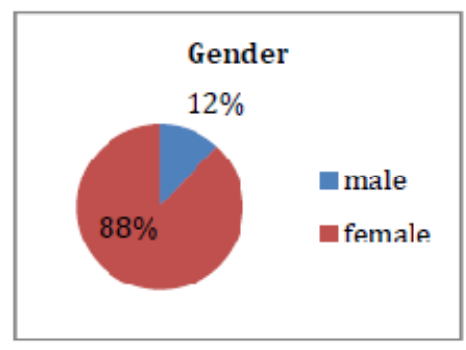

Figure. 2 
Table. 2

\begin{tabular}{|l|l|l|l|}
\hline No: & Female/male & Total & Percentage \\
\hline 1. & Male & 5 & $12 \%$ \\
\hline 2. & Female & 37 & $88 \%$ \\
\hline
\end{tabular}

In the Figure 2 and Table 2, above is a summary of the representation of gender in this study. The male representation are 5 respondents are males and 37 are female responses which provides a unequal representation of gender as the females are $88 \%$ and the males are $12 \%$. With the outcome of the study, it should be known that this study was conducted with more female opinions and few male opinions and the findings should be interpreted likewise. It is always better to have a balanced opinion and that is gathered from a balance in both male and female responses. It is important to note that this variable is not strange coming from the health industry, because worldwide where it is known that fewer males enter the nursing industry and that there is always more females that become nurses, so it relates to the international world. To compare it with the male female intake at UNAM it also relates to that intake, as fewer males are enrolled at the Nursing faculty.

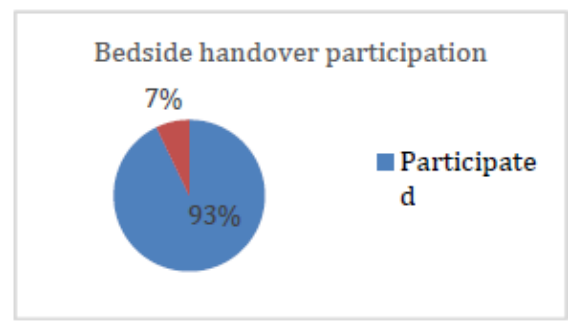

Figure. 3

Table. 3

\begin{tabular}{|l|l|l|l|}
\hline No: & Participation & Total & Percentage \\
\hline 1. & Yes & 39 & 93 \\
\hline 2. & No & 3 & 7 \\
\hline
\end{tabular}

Figure 3 and Table 3 provide data of participation during Bedside Handover. Most of the respondents (93\%) indicated that they have participated in bedside handovers. There was only a mere $7 \%$ that indicated that they did not take part in such procedure. For the study this is valuable to have respondents that are knowledgeable about the issue under investigation and this increase the validity of the study. It is important to know that from the total of 42 students a mere 3\% did not participate and 39\% did take part in bedside handovers. This shows that the respondents are fully aware of the issue they needed to respond on.

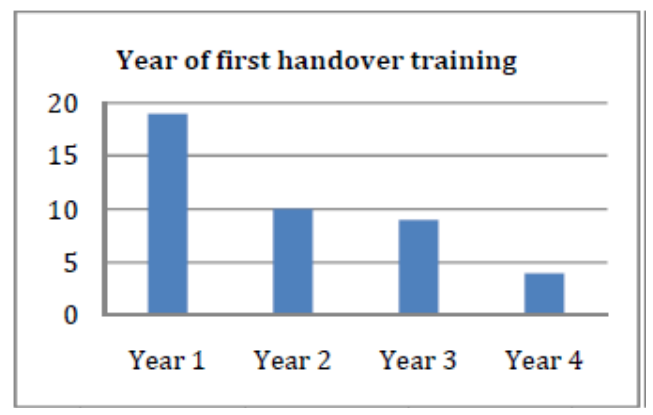

Figure. 4 
South American Journal of Nursing

Special Edition 2016

Table. 4

\begin{tabular}{|l|l|l|l|}
\hline No: & Year of training & Total & Percentage \\
\hline 1 & Year 1 & 19 & 45 \\
\hline 2. & Year 2 & 10 & 24 \\
\hline 3. & Year 3 & 9 & 21 \\
\hline 4 & Year 4 & 4 & 10 \\
\hline
\end{tabular}

The procedure of the first bedside handover is displayed in the data of Figure 4 and Table 4. The data reveals that during the first year off nursing about 45\% (19 participants) already conducted some bedside handovers. During the second year about 224\% of the nursing students (10 participants) who responded in this study die some bedside handovers. In the third year of studies about $21 \%$ of student nurses (9) participants responded in this study. The last group of student nurses (4) that are a $10 \%$ of the total respondents indicated that they only did their first bedside handover during that fourth year of studies.

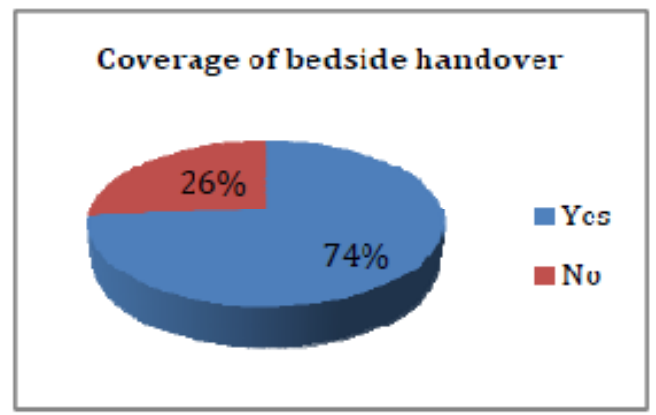

Figure. 5

Table. 6

\begin{tabular}{|l|l|l|l|}
\hline No & Coverage & Total & Percentage \\
\hline 1 & Yes & 31 & 74 \\
\hline 2 & No & 11 & 26 \\
\hline
\end{tabular}

Figure 5 and Table 5, displays data of the coverage of bedside handover. A number of 31 respondents indicated positively that it is covered in their study programme, where 11 respondents denied that it is covered. This means that $74 \%$ of the students nurses feel that they studied about bedside handovers were $26 \%$ felt they did not study about it at all.

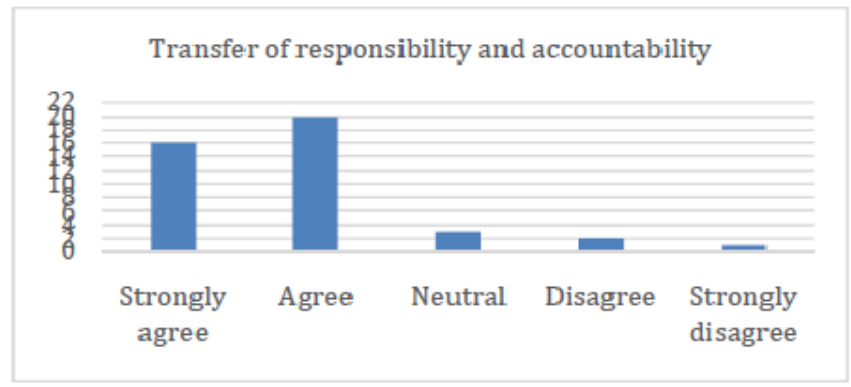

Figure. 6

Table. 6

\begin{tabular}{|l|l|l|l|}
\hline No: & Accountability & Total & Percentage \\
\hline 1 & Strongly agree & 16 & 38 \\
\hline 2. & Agree & 20 & 48 \\
\hline 3. & Neutral & 3 & 7 \\
\hline 4. & Strongly disagree & 2 & 5 \\
\hline 5 & disagree & 1 & 2 \\
\hline
\end{tabular}


In Figure 6 and Table 6 it is displayed how it is perceived to transfer responsibility and accountability concerning bedside handovers. The two highest intensities are the group that agreed which are 16 respondents (38\%) and the other group that strongly agree of 20 respondents and a percentage of $48 \%$. The options of neutral disagree and strongly disagreed totals to 6 respondents that reveal $14 \%$ of the total respondents.

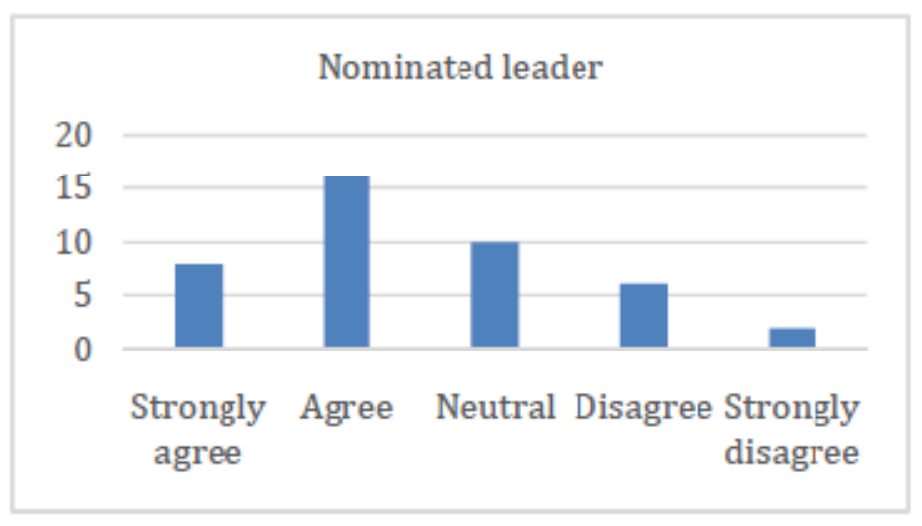

Figure. 7

Table. 7

\begin{tabular}{|l|l|l|l|}
\hline No: & Leader & Total & Percentage \\
\hline 1 & Strongly agree & 8 & 19 \\
\hline 2. & Agree & 16 & 38 \\
\hline 3. & Neutral & 10 & 24 \\
\hline 4. & Strongly agree & 6 & 14 \\
\hline 5 & Agree & 2 & 5 \\
\hline
\end{tabular}

In Figure 7 and Table 7 it is important to realise that respondents indicated that a nominated leader in the team that does the bedside handover rounds in the wards at the hospital.

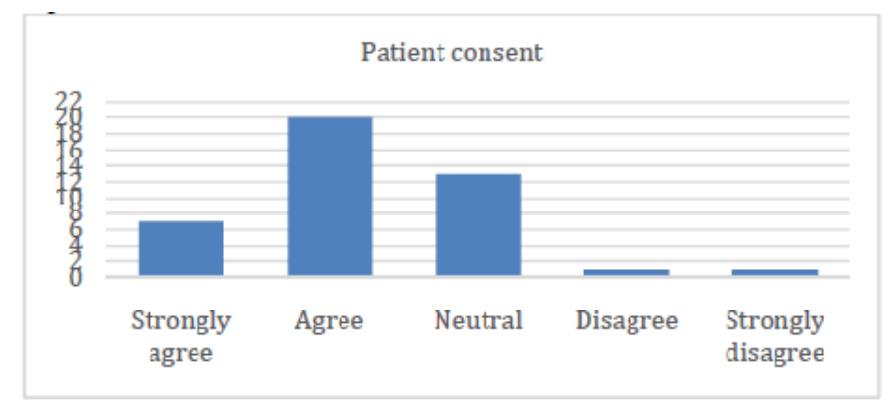

Figure. 8

Table. 8

\begin{tabular}{|l|l|l|l|}
\hline No: & Consent & Total & Percentage \\
\hline 1 & Strongly agree & 7 & 17 \\
\hline 2. & Agree & 20 & 48 \\
\hline 3. & Neutral & 13 & 31 \\
\hline 4. & Strongly disagree & 1 & 2 \\
\hline 5 & disagree & 1 & 2 \\
\hline
\end{tabular}

Figure 8 and Table 8 reveals data about the consent of a patient concerned. There were 7 respondents (17\%) that indicated they strongly believe so and others who are also in agreement are 20 respondents (48\%) of the total group of student nurses. A group of 13 
South American Journal of Nursing

Special Edition 2016

respondents (31\%) of student nurses indicated that they are neutral, but 1 respondent (2\%) indicated that he/she felt to strongly disagree and another 1 respondent (2\%) felt to just disagree.

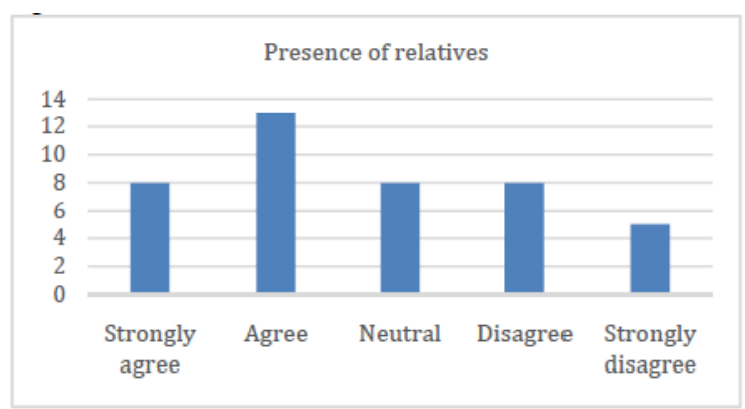

Figure. 9

Table. 9

\begin{tabular}{|l|l|l|l|}
\hline No: & Family presence & Total & Percentage \\
\hline 1 & Strongly agree & 8 & 19 \\
\hline 2. & Agree & 13 & 31 \\
\hline 3. & Neutral & 8 & 19 \\
\hline 4. & Strongly disagree & 8 & 19 \\
\hline 5 & disagree & 5 & 12 \\
\hline
\end{tabular}

Figure 9 and Table 9 reveals data on the opinion of respondents whether there should be relatives present during bedside handovers or not. The highest number plotted is 13 respondents that are $31 \%$ of the student nurses who were part of the population of this study and they all agreed to this statement. The group that strongly agreed at about 8 respondents that amounts to $19 \%$. A further 8 students indicated that they are neutral that amounts to $19 \%$ of the respondents felt to be neutral to this comment. There are 8 respondents (19\%) who strongly disagree and there are 5 respondents (12\%) who disagree.

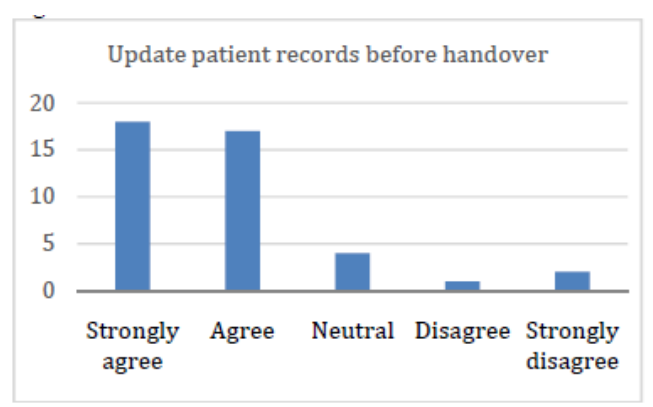

Figure. 10

Table. 10

\begin{tabular}{|l|l|l|l|}
\hline No: & Records & Total & Percentage \\
\hline 1 & Strongly agree & 18 & 43 \\
\hline 2. & Agree & 17 & 40 \\
\hline 3. & Neutral & 4 & 10 \\
\hline 4. & Strongly disagree & 1 & 2 \\
\hline 5 & disagree & 2 & 5 \\
\hline
\end{tabular}

Figure 10 and Table 10 reveals data on the opinion of respondents whether the records of patients should be updated before the bedside handover. There are 17 respondents that are $40 \%$ of the student nurses who were part of the population of this study and they all agreed to this statement. The group that strongly agreed is about 18 respondents that amount to $43 \%$. A 
further 4 students indicated that they are neutral that amounts to $10 \%$ of the respondents felt to be neutral to this comment. There are 1 respondent (2\%) who strongly disagree and there are 2 respondents (5\%) who disagree.

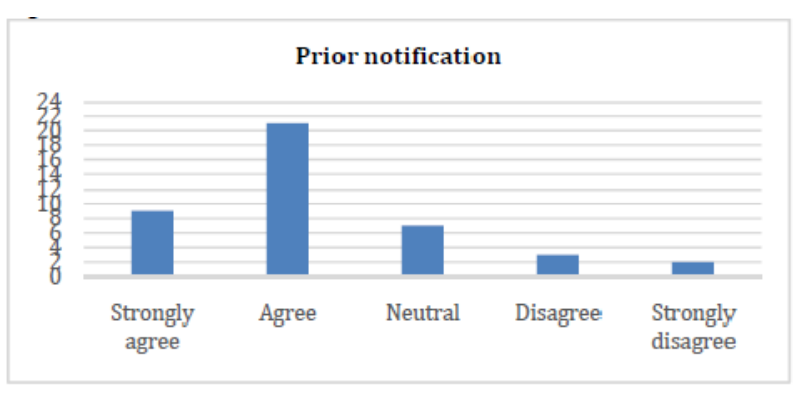

Figure. 11

Table. 11

\begin{tabular}{|l|l|l|l|}
\hline No: & Prior Notification & Total & Percentage \\
\hline 1 & Strongly agree & 9 & 21 \\
\hline 2. & Agree & 21 & 50 \\
\hline 3. & Neutral & 7 & 17 \\
\hline 4. & Strongly disagree & 3 & 7 \\
\hline 5 & disagree & 2 & 5 \\
\hline
\end{tabular}

About prior notification, Figure 11 and Table 11 reveal data on the opinions of respondents. There are 9 respondents (21\%) who were part of the population of this study and they all strongly agreed to this statement. The group that agreed is about 21 respondents (50\%). A further 7 students (10\%) indicated that they are neutral to this comment. There are a further 3 respondents (7\%) who strongly disagree and there are 2 respondents (5\%) who only just disagree.

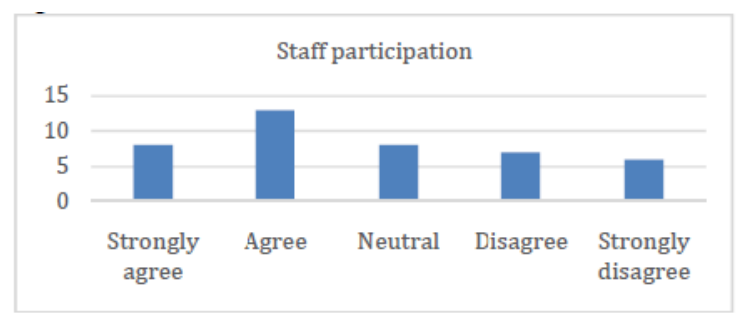

Figure. 12

Table. 12

\begin{tabular}{|l|l|l|l|}
\hline No: & Staff & Total & Percentage \\
\hline 1 & Strongly agree & 8 & 19 \\
\hline 2. & Agree & 13 & 31 \\
\hline 3. & Neutral & 8 & 19 \\
\hline 4. & Strongly disagree & 7 & 17 \\
\hline 5 & disagree & 6 & 14 \\
\hline
\end{tabular}

About staff participation, Figure 12 and Table 12 reveal interesting data on the opinion of respondents. There are 8 respondents (19\%) that strongly agreed to this statement. The group that agreed is about 13 respondents 31\%. A further 8 respondents (19\%) indicated that they are neutral. There are 7 respondents (17\%) who strongly disagree and there are 6 respondents (14\%) who disagree. 
South American Journal of Nursing

Special Edition 2016

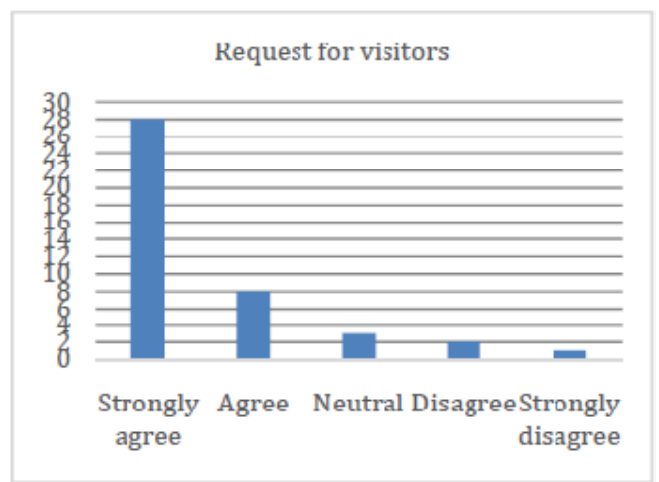

Figure. 13

Table. 13

\begin{tabular}{|l|l|l|l|}
\hline No: & Visitors & Total & Percentage \\
\hline 1 & Strongly agree & 28 & 67 \\
\hline 2. & Agree & 8 & 19 \\
\hline 3. & Neutral & 3 & 7 \\
\hline 4. & Strongly disagree & 2 & 5 \\
\hline 5 & disagree & 1 & 2 \\
\hline
\end{tabular}

In Figure 13 and Table 13 the request for visitors is revealed. There are 28 respondents (67\%) that strongly agreed to this statement. The group that agreed is about 8 respondents (19\%). A further 3 respondents (7\%) indicated that they are neutral. There are 2 respondents (5\%) who strongly disagree and there are 1 respondent (2\%) who disagree.

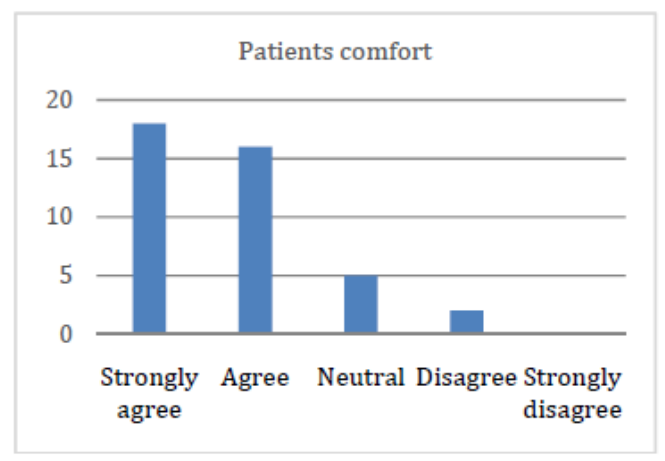

Figure. 14

Table. 14

\begin{tabular}{|l|l|l|l|}
\hline No: & Comfort & Total & Percentage \\
\hline 1 & Strongly agree & 18 & 43 \\
\hline 2. & Agree & 16 & 38 \\
\hline 3. & Neutral & 5 & 12 \\
\hline 4. & Strongly disagree & 2 & 5 \\
\hline 5 & disagree & 0 & 0 \\
\hline
\end{tabular}

In Figure 14 and Table 14 it is displayed how respondents feel about the patient's comfort. Some respondents strongly agreed with the statement and they totaled to 18 with a percentage of $43 \%$. The group that agreed which are 16 respondents (38\%). The options of neutral disagree and strongly disagreed totals to 7 respondents that reveal $17 \%$ of the total respondents. 


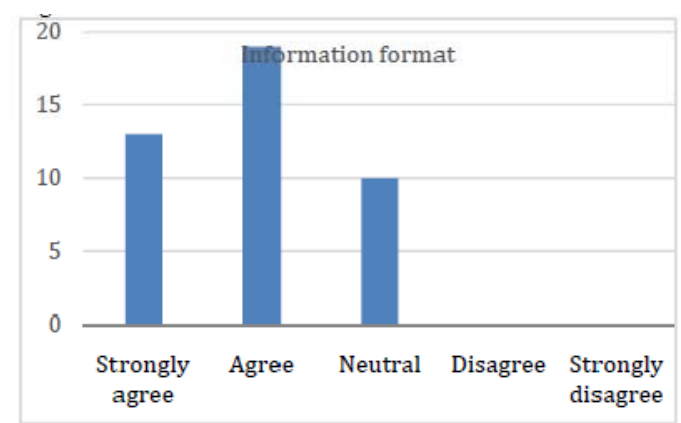

Figure. 15

Table. 15

\begin{tabular}{|l|l|l|l|}
\hline No: & Info format & Total & Percentage \\
\hline 1 & Strongly agree & 13 & 31 \\
\hline 2. & Agree & 19 & 45 \\
\hline 3. & Neutral & 10 & 24 \\
\hline 4. & Strongly disagree & 0 & 0 \\
\hline 5 & disagree & 0 & 0 \\
\hline
\end{tabular}

About the format of the information, Figure 15 and Table 15 reveals the data from the populated sample. There are 13 respondents (31\%) that strongly agreed to this statement. The group that agreed is about 19 respondents 31\%. A further 10 respondents (24\%) indicated that they are neutral. There are no respondents who strongly disagreed or disagreed.

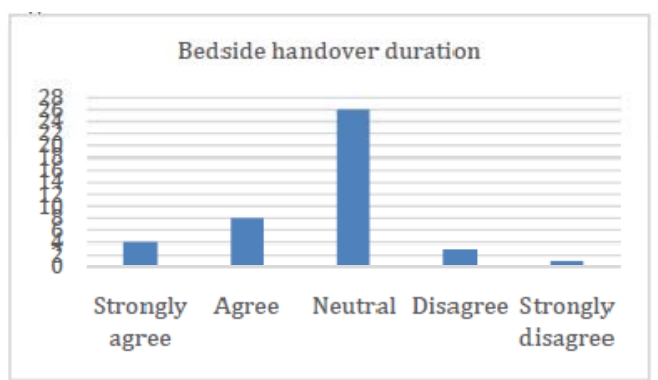

Figure. 16

Table. 16

\begin{tabular}{|l|l|l|l|}
\hline No: & Duration & Total & Percentage \\
\hline 1 & Strongly agree & 4 & 10 \\
\hline 2. & Agree & 8 & 19 \\
\hline 3. & Neutral & 26 & 62 \\
\hline 4. & Strongly disagree & 3 & 7 \\
\hline 5 & disagree & 1 & 2 \\
\hline
\end{tabular}

About the duration of bedside handover duration, Figure 16 and Table 16 reveal all gathered data. There are 4 respondents (10\%) that strongly agreed to this statement. The group that agreed is about 8 respondents 19\%. A further 26 respondents (62\%) indicated that they are neutral. There are 3 respondents (7\%) who strongly disagree and there are 1 respondent (2\%) who disagree. 
South American Journal of Nursing

Special Edition 2016

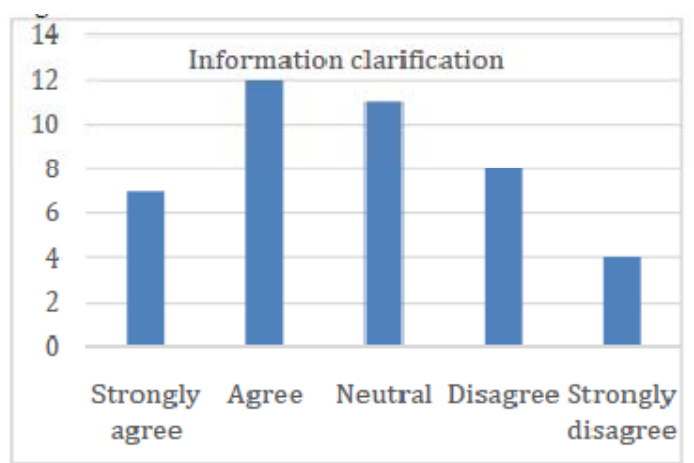

Figure. 17

Table. 17

\begin{tabular}{|l|l|l|l|}
\hline No: & Information clarification & Total & Percentage \\
\hline 1 & Strongly agree & 7 & 17 \\
\hline 2. & Agree & 12 & 29 \\
\hline 3. & Neutral & 11 & 26 \\
\hline 4. & Strongly disagree & 8 & 19 \\
\hline 5 & disagree & 4 & 10 \\
\hline
\end{tabular}

Figure 17 and Table 17 reveals the consideration of importance of information clarification. The 7 respondents (17\%) strongly agreed to the importance of information clarification. The group that agreed is about 12 respondents 29\%. A further 11 respondents (26\%) indicated that they are neutral. There are 8 respondents (19\%) who strongly disagree and there are 4 respondents (10\%) who disagree.

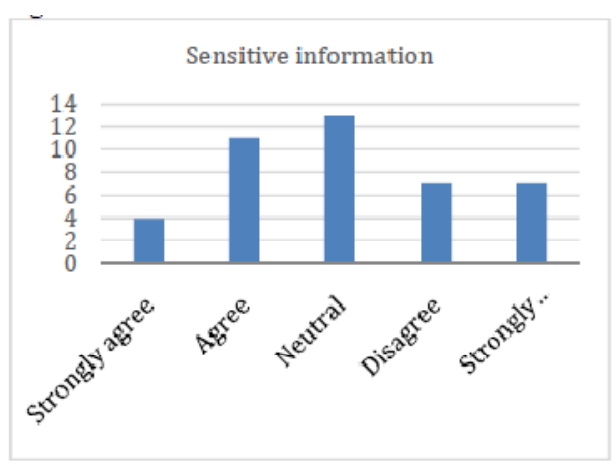

Figure. 18

Table. 18

\begin{tabular}{|l|l|l|l|}
\hline No: & Discharge inclusion & Total & Percentage \\
\hline 1 & Strongly agree & 4 & 10 \\
\hline 2. & Agree & 11 & 26 \\
\hline 3. & Neutral & 13 & 31 \\
\hline 4. & Strongly disagree & 7 & 17 \\
\hline 5 & disagree & 7 & 17 \\
\hline
\end{tabular}

Figure 18 and Table 18 reveals the summary of data concerning the consideration of importance of information clarification. There are 4 respondents (10\%) that feel they strongly agreed to the importance of information clarification. this statement. The group 11 respondents (26\%) that agreed is and a further 13 respondents (31\%) indicated that they are neutral. There are 7 respondents (17\%) who strongly disagree and there are 7 respondents (17\%) who disagree. 


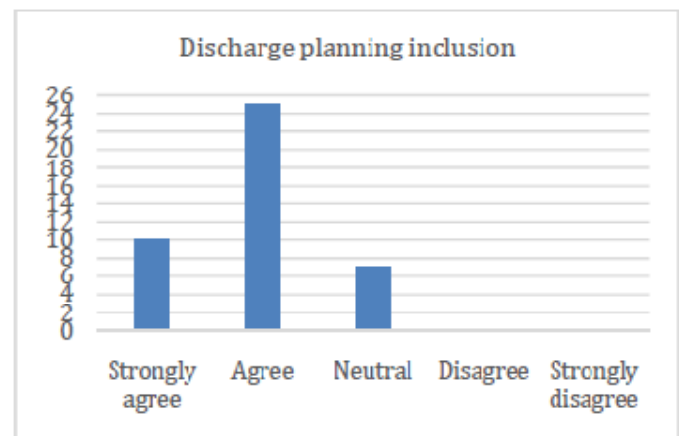

Figure. 19

Table. 19

\begin{tabular}{|l|l|l|l|}
\hline No: & Discharge inclusion & Total & Percentage \\
\hline 1 & Strongly agree & 10 & 24 \\
\hline 2. & Agree & 25 & 60 \\
\hline 3. & Neutral & 7 & 17 \\
\hline 4. & Strongly disagree & 0 & 0 \\
\hline 5 & disagree & 0 & 0 \\
\hline
\end{tabular}

Figure 19 and Table 19 reveals the discharge planning inclusion. The 10 respondents (24\%) that strongly agreed to the importance of discharge planning inclusion. The group that agreed is about 25 respondents (60\%). A further 7 respondents $(17 \%)$ indicated that they are neutral. There is nobody who responded on strongly disagreeing or who disagrees.

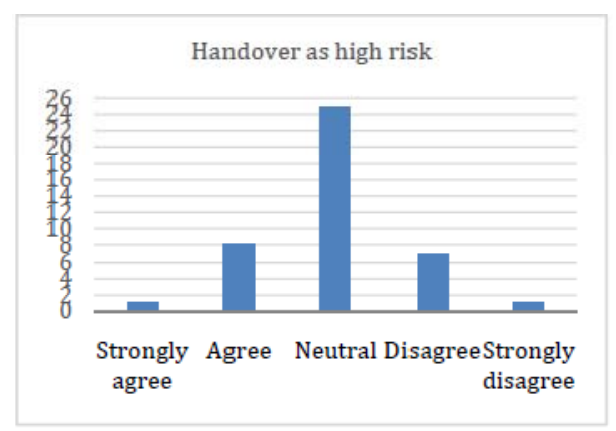

Figure. 20

Table. 20

\begin{tabular}{|l|l|l|l|}
\hline No: & High risk & Total & Percentage \\
\hline 1 & Strongly agree & 1 & 2 \\
\hline 2. & Agree & 8 & 19 \\
\hline 3. & Neutral & 25 & 60 \\
\hline & & & \\
\hline 4. & Strongly disagree & 7 & 17 \\
\hline 5 & disagree & 1 & 2 \\
\hline
\end{tabular}

In Figure 20 and Table 20 data reveal that the Bedside Handover activity is considered as a highly important activity. From the total sample 1 respondent (2\%) strongly agreed. The group that who agreed is about 8 respondents 19\%. A further 25 respondents (60\%) indicated that they are neutral. There are 7 respondents (17\%) who strongly disagree and there are 1 respondent (2\%) who disagree. 
South American Journal of Nursing

Special Edition 2016

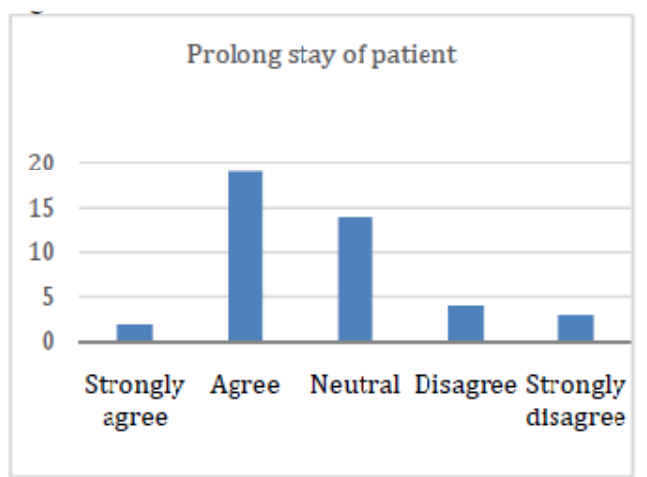

Figure. 21

Table. 21

\begin{tabular}{|l|l|l|l|}
\hline No: & Delayed treatment & Total & Percentage \\
\hline 1 & Strongly agree & 2 & 5 \\
\hline 2. & Agree & 19 & 45 \\
\hline 3. & Neutral & 14 & 33 \\
\hline 4. & Strongly disagree & 4 & 16 \\
\hline 5 & disagree & 2 & 7 \\
\hline
\end{tabular}

In Figure 21 and Table 21 data reveal the cause of incorrect bedside handover procedures and it indicates that it causes prolonged stay of the patient in the hospital. The 2 respondents (5\%) strongly agreed to the importance of information clarification. this statement. The group that agreed is about 19 respondents $45 \%$. A further 14 respondents (33\%) indicated that they are neutral. There are 4 respondents (16\%) who strongly disagree and there are 2 respondents (7\%) who disagree.

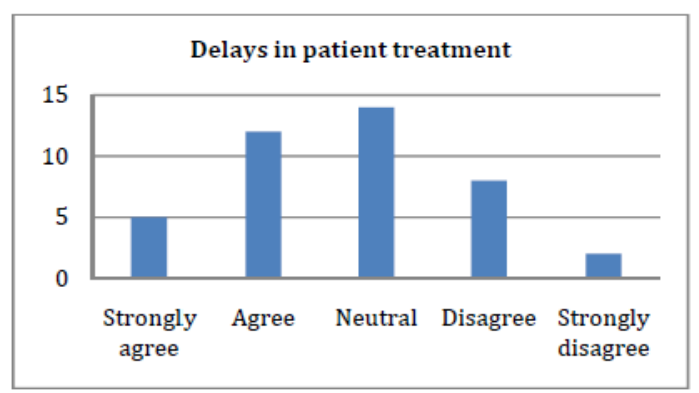

Figure. 22

Table. 22

\begin{tabular}{|l|l|l|l|}
\hline No: & Patient stay & Total & Percentage \\
\hline 1 & Strongly agree & 2 & 5 \\
\hline 2. & Agree & 19 & 45 \\
\hline 3. & Neutral & 14 & 33 \\
\hline 4. & Strongly disagree & 4 & 16 \\
\hline 5 & disagree & 2 & 7 \\
\hline
\end{tabular}

Figure 22 and Table 2 reveal data of delaying of the treatment of patients if bedside handover was not correctly conducted. The 2 respondents (5\%) strongly agreed to the importance of information clarification. this statement. The group that agreed is about 19 respondents $45 \%$. A further 14 respondents (33\%) indicated that they are neutral. There are 4 respondents (16\%) who strongly disagree and there are 2 respondents (7\%) who disagree. 


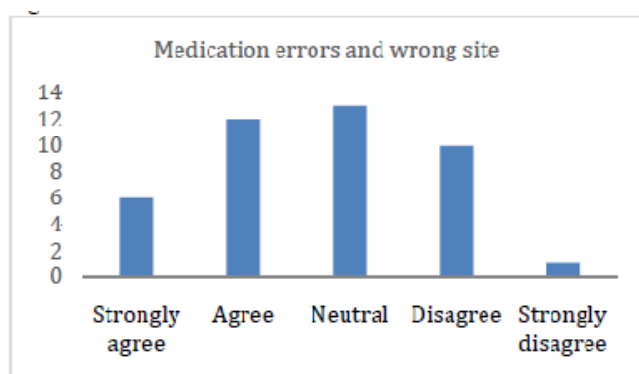

Figure. 23

Table. 23

\begin{tabular}{|l|l|l|l|}
\hline No: & Medication error & Total & Percentage \\
\hline 1 & Strongly agree & 6 & 14 \\
\hline 2. & Agree & 12 & 29 \\
\hline 3. & Neutral & 13 & 31 \\
\hline 4. & Strongly disagree & 10 & 24 \\
\hline 5 & disagree & 1 & 2 \\
\hline
\end{tabular}

Figure 23 and Table 23 the data reveal the influence of medical error. The 6 respondents (14\%) strongly agreed to the importance of information clarification. this statement. The group that agreed is about 12 respondents $29 \%$. A further 13 respondents (31\%) indicated that they are neutral. There are 10 respondents (24\%) who strongly disagree and there are 1 respondent (2\%) who disagree.

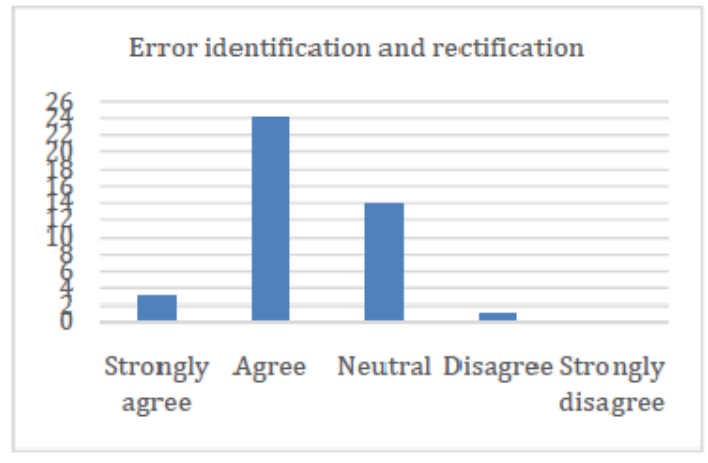

Figure. 24

Table. 24

\begin{tabular}{|l|l|l|l|}
\hline No: & Error rectification & Total & Percentage \\
\hline 1 & Strongly agree & 3 & 7 \\
\hline 2. & Agree & 24 & 57 \\
\hline 3. & Neutral & 14 & 33 \\
\hline 4. & Strongly disagree & 1 & 2 \\
\hline 5 & disagree & 0 & 0 \\
\hline
\end{tabular}

Figure 24 and Table 24 the data reveal that bedside handover allows room for error rectification. There are 3 respondents (7\%) strongly agreed to the importance of information clarification. this statement. The group that agreed is about 24 respondents 57\%. A further 14 respondents (33\%) indicated that they are neutral. There are 1 respondent (2\%) who strongly disagree and there are no respondents who disagree. 
South American Journal of Nursing

Special Edition 2016

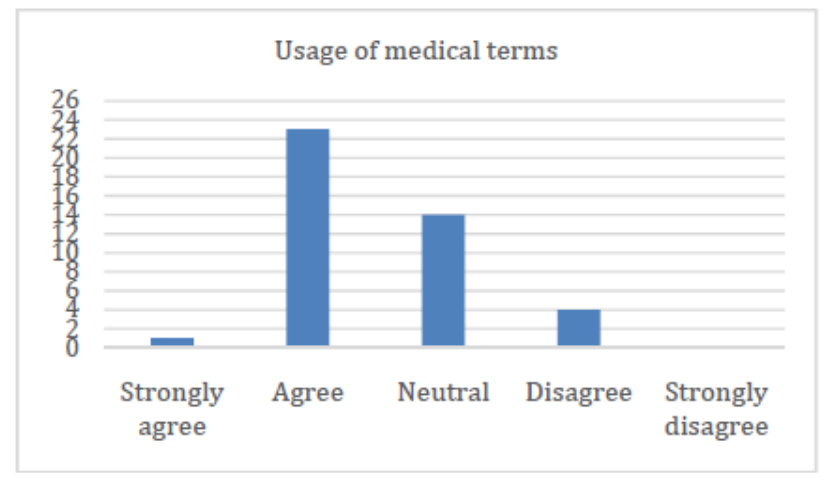

Figure. 25

Table. 25

\begin{tabular}{|l|l|l|l|}
\hline No: & Medical terms & Total & Percentage \\
\hline 1 & Strongly agree & 1 & 2 \\
\hline 2. & Agree & 23 & 55 \\
\hline 3. & Neutral & 14 & 33 \\
\hline 4. & Strongly disagree & 4 & 10 \\
\hline 5 & disagree & 0 & 0 \\
\hline
\end{tabular}

Figure 25 and Table 25 reveal the importance of the use of medical terms. The 1 respondent (2\%) strongly agreed to the importance of information clarification. this statement. The group that agreed is about 23 respondents 55\%. A further 14 respondents (33\%) indicated that they are neutral. There are 4 respondents $(10 \%)$ who strongly disagree and there are no respondents who disagree.

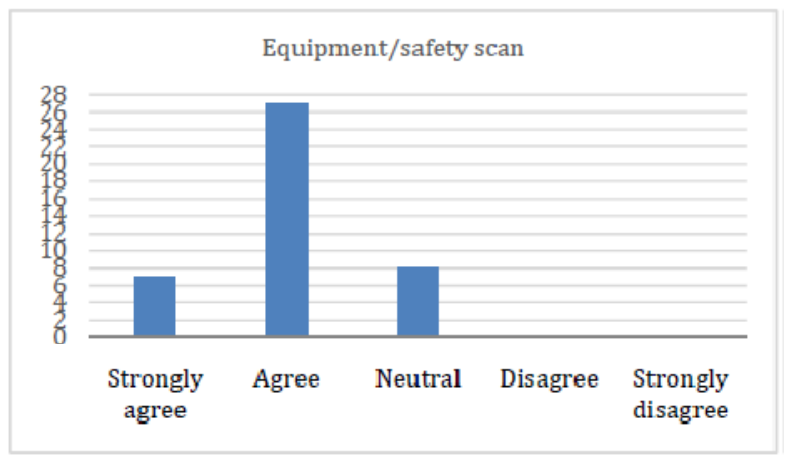

Figure. 26

Table. 26

\begin{tabular}{|l|l|l|l|}
\hline No: & Equipment & Total & Percentage \\
\hline 1 & Strongly agree & 7 & 17 \\
\hline 2. & Agree & 27 & 64 \\
\hline 3. & Neutral & 8 & 19 \\
\hline 4. & Strongly disagree & 0 & 0 \\
\hline 5 & disagree & 0 & 0 \\
\hline
\end{tabular}

Figure 26 and Table 26 reveal data about the equipment scan. From the total population there are 7 respondents $(17 \%)$ strongly agreed to the importance of information clarification. this statement. The group that agreed is about 27 respondents 64\%. A further 8 respondents (19\%) indicated that they are neutral. There are no respondents who strongly disagree as well as no respondents who disagree. 


\subsection{Findings and discussion}

The data collected was organized and condensed in a way that it was manageable and themes were created from the objectives of the research study. The data is integrated and presented in this paper in the form of (Table 1 above) descriptive narrative under the objectives as the themes. Themes were created for the content analysis namely:-

- The organizational feature bedside handover procedure

- To indentify the perils during bedside handover

- To verify the knowledge of practical application of bedside handover

\subsubsection{The organizational feature bedside handover procedure}

Handover is fundamentally a nursing activity that determines the quality of care that the patients will receive Sherlock (1995). A nurse has a professional responsibility toward the well- organized bedside handover preparation. Chaboyer (2010)stated handover needs to be well- organized with an leader elect, the finding shows a 57\% respondent on the scale of strongly agree to agree, although the positive margin is high, a worrisome $24 \%$ being indecisive, and $19 \%$ disagrees this indicates that it is less important to receive instructions. On the contrary, this will affect the selection and allocation of staff members who are nominated to ensure continuity of patient care, $50 \%$ respondent positively that staff allocation is crucial and $19 \%$ are neutral and $31 \%$ negatively opposed the importance of continues care. The neutral and negatively agreed respondent comprises of $50 \%$ of the total population of the study. The knowledge of staff thus is less responsibility of ensuring continues handover and maximizing the utilization of staff available. A study was conducted in Namibia about health work force shortages and some inequities in their distribution of work are stated in the findings in a case study (McQuide 2013).

This study confirms that most of the respondents (86\%) in which $38 \%$ and $48 \%$ provided strongly to agree responses on the scale. However, an insignificant amount of $18 \%$ ranging from neutral to strongly disagreement was among respondents of indicating the responsibility to the bedside handover. Furthermore, responses regarding the preparation related issues are demonstrating a conflicting pattern, as one of the responsibilities in bedside handover preparation is to avoid interruptions, which according to Brixey (2005) is a frequent event within health care settings. In Table: 1 below is contributing activities that may cause interruptions during bedside handover if not managed properly.

Notification of handover to the patient and staff members ensures readiness and willingness for the procedure and it minimizes unnecessary traffic in ward. Consequently it gives an opportunity to reconfirm the consent of the patient to participate in the process. The finding indicates a positive response $71 \%$ in favor of prior notification and $17 \%$ neutral, and $10 \%$ disagreed negatively. Surprisingly, the respondent draws a picture of patient's consent disregarded in bedside handover $17 \%$ hence, $65 \%$ do support that the patient consent that should be obtained before the process.

The family plays a supportive role in the patient care, and may assist to alleviate hospital anxiety by being companions to the patient. The results below indicate an equal split $50 \%$ of the respondents values the presence of the family at handover and the other $50 \%$ of the respondents are divided amongst $19 \%$ who are neutral to $31 \%$ of the respondent that disagrees in their responses.

The responses of the visitors indicate a hospitable value of $86 \%$ of the respondents that agrees to the fact that visitors should leave the ward before bedside handover. In this way the integrity of the patient is surely safe guarded. However, privacy should be maintained for instance, the staff to lower their voices (confidentiality and privacy) pitch neutral and be friendlier and more caring to the patients.

The table below is a summary of how to conduct bedside handovers per opinion of the respondents of this study. 
South American Journal of Nursing

Special Edition 2016

Table. 1

\begin{tabular}{|l|l|l|l|l|l|l|}
\hline & Beside Handover Preparation & & \multicolumn{5}{|l|}{} \\
\hline $\mathbf{1}$ & $\begin{array}{l}\text { Prior notification and alertness of the pending } \\
\text { handover process to the patient is imperative }\end{array}$ & 9 & 21 & 7 & 3 & 1 \\
\hline & Percentage of respondent & $21 \%$ & $50 \%$ & $17 \%$ & $7 \%$ & $3 \%$ \\
\hline $\mathbf{2}$ & May patient's relatives be allowed at the handover & 8 & 13 & 8 & 8 & 5 \\
\hline & Percentage of respondent & $19 \%$ & $31 \%$ & $19 \%$ & $19 \%$ & $12 \%$ \\
\hline $\mathbf{3}$ & $\begin{array}{l}\text { Prior handover visitors should be requested to leave } \\
\text { ensue privacy }\end{array}$ & 28 & 8 & 3 & 2 & 1 \\
\hline & Percentage & $67 \%$ & $19 \%$ & $7 \%$ & $5 \%$ & $2 \%$ \\
\hline $\mathbf{4}$ & Patient's consent & 7 & 20 & 13 & 1 & 1 \\
\hline & Percentage & $17 \%$ & $20 \%$ & $13 \%$ & $1 \%$ & $1 \%$ \\
\hline
\end{tabular}

Updating of the patient record before bedside handover is fundamental in the nursing bedside handover as it provides an opportunity to indentify lost written information and it may serve as backup tool for verbal communication. Webster (1999) reported that information obtained at handover, provides nurses with little detail about the patient, the nursing needs or the effectiveness of the previous. In Table: 2 below indicate, majority of $83 \%$ the respondent value the importance of a records that should be updated to be current and congruent with patient's condition. However, a merely 7\% disagree. The patient comfort is a very important aspect as it increases the patient's engagement. Most $81 \%$ of the respondent agreed with patients comfort whilst $12 \%$ are neutral and mere $5 \%$ are opposing the notion. The table below is a summary of how to conduct bedside handover as per opinion of the respondent.

Table. 2

\begin{tabular}{|c|c|c|c|c|c|c|}
\hline \multirow[b]{2}{*}{1} & \multicolumn{6}{|l|}{ Beside Handover Preparation } \\
\hline & $\begin{array}{l}\text { Patient record should be updated prior to the hand } \\
\text { over process }\end{array}$ & 18 & 17 & 4 & 1 & 2 \\
\hline & Percentage of respondent & 43 & $40 \%$ & $10 \%$ & $2 \%$ & $5 \%$ \\
\hline 2. & $\begin{array}{l}\text { Patient comfort (e.g. pain free) should be ensured } \\
\text { before handover commences }\end{array}$ & 18 & 16 & 5 & 2 & 0 \\
\hline & Percentage of respondent & $43 \%$ & $38 \%$ & $12 \%$ & $5 \%$ & $0 \%$ \\
\hline
\end{tabular}

\subsubsection{To Identify the Perils of Bedside Handovers}

Threats to patient safety during clinical handover have been identified as an ongoing problem (Botti 2009).Therefore, it's crucial to ensure that the information is conveyed is, in current, knowledgeable and detailed way (Parker, (2004).

The respondent indicates an infrequent rating regarding the bedside handover as a risk event, majority $60 \%$ are indecisive and 21\% do agree to be a risky procedure $19 \%$ disagree.

Medication errors and wrong procedures respondent $41 \%$ are recognizing this fatal danger, $31 \%$ are indecisive and $26 \%$ do not agree that bedside could adversely implicate the patients outcome.

However, respondent indicates a consistency in one aspect in both that bedside handover prolongs patient hospital stay and delays in treatment with even rates 33\% being neutral and with the trend of $50 \%$ and $45 \%$ agreeing respectively whilst a non significant difference responses poses by those who disagree ranging from 23\%-24\% respectively. Furthermore, (Kaur 2014) argues that safe nursing practice needs an understanding of the legal boundaries, and in bedside handover is to be legally accountable for one's action. Additionally, it is reported that gaining knowledge raises awareness of personal and professional accountability and the dilemmas of practices (Hall 2006:34).

Therefore, is imperative the nurse to be aware of possible danger embedded in the bedside handover procedure in order to increase its accuracy, effectiveness and patient safety. 
The table below is a summary of how to conduct bedside hand over as per opinion of the respondent.

Table. 3

\begin{tabular}{|c|c|c|c|c|c|c|}
\hline & Bedside Handover Perils & & & & & \\
\hline \multirow[t]{2}{*}{1} & Hand over is a high risk event & 1 & 8 & 25 & 7 & 1 \\
\hline & Percentage of respondent & $2 \%$ & $19 \%$ & $60 \%$ & $17 \%$ & $2 \%$ \\
\hline \multirow[t]{2}{*}{2} & $\begin{array}{l}\text { Handover can cause medication errors and wrong } \\
\text { procedures }\end{array}$ & 6 & 12 & 13 & 10 & 1 \\
\hline & Percentage of respondent & $14 \%$ & $29 \%$ & $31 \%$ & $24 \%$ & $2 \%$ \\
\hline \multirow[t]{2}{*}{3} & Handover may prolonged stay of patient in the hospital & 2 & 19 & 14 & 4 & 2 \\
\hline & Percentage of respondent & $5 \%$ & $45 \%$ & $33 \%$ & $16 \%$ & $7 \%$ \\
\hline \multirow[t]{2}{*}{4} & $\begin{array}{l}\text { Bedside handover creates delays in patient treatment } \\
\text { and care }\end{array}$ & 5 & 12 & 14 & 8 & 2 \\
\hline & Percentage & $12 \%$ & $29 \%$ & $33 \%$ & $19 \%$ & $5 \%$ \\
\hline
\end{tabular}

\section{Conclusion and recommendations}

In conclusion, this study of bedside handover amongst final year nursing students in a Namibian training institute provides a description of the knowledge and underrating of the bed handover's structures, processes and adverse events that could arise during the process this information may be used as of training the pre service students for more effective practical application This study may give an opportunity for the following: To replicate a similar study with a larger sample. To conduct an observational study to observe any changes in practice of nurses after providing them with adequate knowledge concerning bedside handover Finally, to contact a study to assess knowledge, practice and attitude of nurses regarding bedside handover in nursing care.

\section{References}

[1.] American Medical Association. Opinion 10.05 Potential patients. Code of Medical Ethics. Available at: Potential Patients. Accessed April 24, 2006. Bomba DTPR. A description of handover processes in an Australian public hospital. Aust Health Rev 2005; 29:68-79.

[2.] Qual Saf Health Care. 2008 Feb; 17(1):6-10. doi: 10.1136/qshc.2006.019273. Adequacy of information transferred at resident sign-out (in hospital handover of care): a prospective survey. Borowitz SM${ }^{1}$, Waggoner-Fountain LA, Bass EJ, Sledd RM.

[3.] Chaboyer W, McMurray A, Johnson J, Hardy L, Wallis M, Chu FY. Bedside Handover: Quality Improvement Strategy to "Transform Care at the Bedside". (in press). Journal of Nursing Care Quality (prepublication print).

[4.] Alvarez, G., \& Coiera, E. (2006). Interdisciplinary communication: An uncharted source of medical error? Journal of Critical Care, 21(3), 236-242.

[5.] McKenna L and Walsh K. (1997) Changing handover practices: one private hospital's experiences. Int J Nurs Pract; 3(2): 128-32.

[6.] Manse T. (2013) Fragmentation of patient safety research: a critical reflection of Current human factors approaches to patient handover, Journal of Public Health Research Vol23:e233

[7.] Thurgood, Graham (1995) Verbal handover reports: what skills are needed? British journal of nursing, 4 (12). pp. 720-722. ISSN 0966-0461

[8.] Alvarado, K. (2007). Transfer of Accountability: Advancing Patient Safety Through Shift-to-Shift Communication Standards. Paper presented at the Improving clinical handover: sharing the lessons learnt, Sydney, N.S.W., Australia

[9.] Pothier D, Monteiro P, Mooktiar M, Shaw A. (2005) Pilot study to show the loss of important data in nursing handover. Br J Nurs; 14(20): 1090-3.

[10.] Hughes RG 2008 Handoffs: Implications for Nurses - Patient Safety and Quality www.ncbi.nlm.nih.gov > NCBI > Literature > Bookshelf

[11.] Kaur H, Kaur JS, Sharma K (2014) A Study to Assess the Knowledge Regarding Legal 
South American Journal of Nursing

Special Edition 2016

Responsibilities in Nursing Vol. 2, Issue 1, (50-53), www.researchpublish.com

[12.] Pfaff K. A; Baxter, P.E ; Jack, S; Ploeg MJ; 2014 Exploring new graduate nurse confidence in interprofessional collaboration: A mixed methods study

[13.] Cresswell, K. M., Fernando, B., McKinstry, B., \& Sheikh, A. (2007). Adverse drug events in the elderly.British Medical Bulletin, 83(1), 259-274. doi: 10.1093/bmb/ldm01

[14.] Parker J, Gardner G, Wiltshire J. Handover: the collective narrative of nursing practice. Australian Journal of Advanced Nursing 1992; 9: 31-37.

[15.] Joint Commission International: WHO Collaborating Centre for Patient Safety and High 5s Initiative.

[http://www.jointcommissioninternational.org/WHO-Collaborating-Centre-for-Patient-Safety-

Solutions/]

[16.] Wood K, Crouch R, Rowland E, Pope C (2014) Clinical handovers between prehospital and hospital staff: literature review. Emerg Med J. 2014 Sep 1. pii: emermed-2013-203165. doi: 10.1136/emermed-2013-203165.

[17.] Brixey JJ, Robinson DJ, Tang Z, Johnson TR, Zhang J, Turley JP (2005):86-90. Interruptions in workflow for RNs in a Level One Trauma Center. AMIA Annu Symp Proc.

[18.] Jeffcott, S.A., Evans, S.M., Cameron, P.A., Chin, G. \& Ibrahim, J.E. 2009. Improving measurement in clinical handover. Quality \& Safety in Health Care. 18(4):272-277.

[19.] McCann, L., McHardy, K. \& Child, S. 2007. Passing the buck: clinical handovers at a tertiary hospital. New Zealand Medical Journal. 120(1264):U2778-U2778.

[20.] McMurray, A., Chaboyer, W., Wallis, M. \& Fetherston, C. 2010. Implementing bedside handover: strategies for change management. Journal of Clinical Nursing. 19(17):2580-2589.

[21.] O'Connell, B. \& Penney, W. 2001. Challenging the handover ritual: recommendations for research and practice. Collegian. 8(3):14-18. O'Connell, B., Macdonald, K. \& Kelly, C. 2008.

[22.] Parker, J. 1996. Handovers in a changing health care climate. Nursing Journal. 4(5):22-26.

[23.] Webster, J. 1999. Practitioner-centred research: an evaluation of the implementation of the bedside hand-over. Journal of Advanced Nursing. 30(6):1375-1382.

[24.] Wilson, M.J. 2007. A template for safe and concise handovers. MEDSURG Nursing. 16(3):201-200.

[25.] Med J Aust. 2009 Jun 1;190(11 Suppl):S157-60. Examining communication and team performance during clinical handover in a complex environment: the private sector post-anaesthetic care unit.

[26.] Botti $\mathrm{M}^{1}$, Bucknall T, Cameron P, Johnstone MJ, Redley B, Evans S, Jeffcott S Sherlock, C. (1995). The patient handover: A study of its form, function and efficiency. Nursing Standard, 9(52), 33-36. Case study Applying the workload indicators of staffing need (WISN) method in Namibia: challenges and implications for human resources for health policy Pamela

[27.] A McQuide ${ }^{{ }^{*}}$, Riitta-Liisa Kolehmainen-Aitken ${ }^{z}$ and Norbert Forster Human Resources for Health 2013, 11:64 doi:10.1186/1478-4491-11-64 The electronic version of this article is the complete one and can be found online at: http://www.human-resources-health.com/content/11/1/64

[28.] Chaboyer W, McMurray A, Wallis M. Bedside nursing handover: A case study. International Journal of Nursing Practice 2010; 16:27-34.

[29.] Kerr MP. A qualitative study of shift handover practice and function from a socio-technical perspective. Journal of Advanced Nursing. 2002;37(2):125-34 Wolf Z. Learning the professional jargon of nursing during change of shift report. Holistic Nursing Practice. 1989;4:78-83. 